\title{
Contribution of diacylglycerol lipase $\beta$ to pain after surgery
}

This article was published in the following Dove Press journal: Journal of Pain Research

\author{
Jennifer Luk' \\ Yong Lu' \\ Amanda Ackermann' \\ Xiaoxue Peng' \\ Diane Bogdan' \\ Michelino Puopolo' \\ David E Komatsu² \\ Simon Tong ${ }^{3}$ \\ Iwao Ojima ${ }^{3,4}$ \\ Mario J Rebecchi' \\ Martin Kaczocha ${ }^{1,4}$ \\ 'Department of Anesthesiology, \\ ${ }^{2}$ Department of Orthopedics, \\ ${ }^{3}$ Department of Chemistry, ${ }^{4}$ Institute \\ of Chemical Biology and Drug \\ Discovery, Stony Brook University, \\ Stony Brook, NY, USA
}

Background: Metabolism of the endocannabinoid 2-arachidonoylglycerol (2-AG) yields arachidonic acid (AA), the precursor to proalgesic eicosanoids including prostaglandin E2 $\left(\mathrm{PGE}_{2}\right.$ ). Diacylglycerol lipase $\beta$ (DAGL $\beta$ ) is an enzyme that synthesizes $2-\mathrm{AG}$ and its inhibition reduces eicosanoid levels and produces antinociceptive effects in models of inflammatory pain. Here we test whether inhibition of DAGL $\beta$ produces antinociceptive effects in a model of postoperative pain.

Methods: Rats were administered the selective DAGL $\beta$ inhibitor KT109 or vehicle and underwent plantar incision. Postsurgical pain/disability was examined using evoked (mechanical hyperalgesia), functional (incapacitance/weight bearing), and functional/spontaneous (locomotion) modalities.

Results: Activity-based protein profiling confirmed that KT109 inhibited DAGL $\beta$ in the lumbar spinal cord (LSC) and brain, confirming that it is a systemically active DAGL $\beta$ inhibitor. Treatment with KT109 reduced basal 2-AG, AA, and PGE $_{2}$ levels in the liver but not the brain, indicating that DAGL $\beta$ activity does not significantly contribute to basal $\mathrm{PGE}_{2}$ production within the central nervous system. Plantar incision elevated the levels of 2-AG and $\mathrm{PGE}_{2}$ in the LSC. Although KT109 did not alter postsurgical 2-AG levels in the LSC, it slightly reduced PGE levels. In contrast, the clinically efficacious cyclooxygenase inhibitor ketoprofen completely suppressed PGE $_{2}$ levels in the LSC. Similarly, KT109 had no significant effect upon postsurgical 2-AG, AA, or PGE ${ }_{2}$ levels at the incision site, while ketoprofen abolished $\mathrm{PGE}_{2}$ production at this location. KT109 and ketoprofen reversed the weight bearing imbalance induced by plantar incision, yet neither KT109 nor ketoprofen had any significant effect on mechanical hyperalgesia. Treatment with ketoprofen partially but significantly rescued the locomotor deficit induced by incision while KT109 was without effect.

Conclusion: DAGL $\beta$ is not the principal enzyme that controls $2-\mathrm{AG}$ derived AA and $\mathrm{PGE}_{2}$ production after surgery, and inhibitors targeting this enzyme are unlikely to be efficacious analgesics superior to those already approved to treat acute postoperative pain.

Keywords: pain, incision, surgery, endocannabinoid, 2-AG

\section{Introduction}

Most surgical procedures induce significant acute postoperative pain that can be difficult to treat despite the use of multimodal analgesic regimens that include the combined use of opioids and cyclooxygenase (COX) inhibitors. ${ }^{15}$ Morphine is the mainstay treatment for acute postsurgical pain, while COX inhibitors are often used as primary or adjunct analgesics. ${ }^{2,8,17,29,31}$ However, perioperative administration of opioids can lead to respiratory depression, paralytic ileus, and increased risk of addiction, and in patients
Correspondence: Martin Kaczocha Department of Anesthesiology, Stony Brook University, Health Sciences Center, L4-077, Stony Brook, NY I I794-8480, USA

Email martin.kaczocha@stonybrook.edu 
with a history of opioid use, further complications during recovery. ${ }^{11,26,41}$ Similarly, use of COX inhibitors increases the risk of postoperative bleeding, most prominently in older patients and in those with cardiovascular disease. ${ }^{14,19,20}$ Therefore, there is a need to develop novel non-opioid analgesics that lack these harmful side effects and are suitable for use during the perioperative period.

The endocannabinoid 2-arachidonoylglycerol (2-AG) is an endogenous ligand for cannabinoid receptors and produces antinociceptive effects in animal models of inflammatory, visceral, and neuropathic pain. ${ }^{3,22,37}$ The hydrolysis of 2-AG yields arachidonic acid (AA), which serves as a substrate for COX enzymes that contribute to the production of a variety of eicosanoids including prostaglandin E2 ( $\left.\mathrm{PGE}_{2}\right)$. Surgical procedures increase $\mathrm{PGE}_{2}$ levels at the surgical site and spinal cord, and COX inhibitors reduce $\mathrm{PGE}_{2}$ production and alleviate postoperative pain. ${ }^{6,8,10,34,49}$ Recent work strongly suggests an important link between the endocannabinoid and eicosanoid systems, wherein downstream 2-AG metabolism produces AA that is subsequently converted into eicosanoids. ${ }^{36}$

The principal pathway for 2-AG biosynthesis involves the enzymatic release of 2-AG from diacylglycerol that is catalyzed by two related enzymes, diacylglycerol lipase alpha (DAGL $\alpha$ ) and diacylglycerol lipase beta (DAGL $\beta$ ). DAGL $\alpha$ is the main enzyme that synthesizes $2-A G$ in neural tissues, whereas DAGL $\beta$ synthesizes $2-A G$ in cells of immune origin such as macrophages and microglia. ${ }^{13,21,43,45}$ Previous work has shown that macrophages derived from DAGL $\beta$-knockout mice or mice treated with the selective irreversible DAGL $\beta$ inhibitor KT109 demonstrate reduced inflammatory effects, characterized by decreased production of 2-AG, eicosanoids, and cytokines after challenge with lipopolysaccharide. ${ }^{21}$ DAGL $\beta$-knockout mice and mice treated with KT109 also show antinociceptive effects in a model of inflammatory pain. ${ }^{46}$ In contrast to DAGL $\beta$, inhibition of DAGL $\alpha$ reduces brain and spinal 2-AG levels, induces anxiety, and may exacerbate pain. ${ }^{13,18,24,40,43}$ The contribution of DAGL $\beta$ activity toward 2-AG and eicosanoid production during the postoperative period has not been examined. The goal of this work was to explore whether DAGL $\beta$ inhibition reduces postsurgical $\mathrm{PGE}_{2}$ production and postsurgical pain in rats.

\section{Materials and methods Drugs and chemicals}

Ketoprofen, 2-AG, $\mathrm{PGE}_{2}, \mathrm{AA}, \mathrm{d}_{5}-2-\mathrm{AG}, \mathrm{d}_{4}-\mathrm{PGE}_{2}$, and $\mathrm{d}_{8}-\mathrm{AA}$ were obtained from Cayman Chemical (Ann Arbor, MI, USA). Mass spectrometry-grade chloroform, methanol, acetonitrile, dimethylsulfoxide (DMSO), and water were obtained from Thermo Fisher Scientific (Waltham, MA, USA).

\section{Animals}

All experiments were performed in accordance with the National Institutes of Health Guidelines for the Care and Use of Laboratory Animals and were approved by the Stony Brook University Institutional Animal Care and Use Committee (protocol \#564663). This study utilized male Sprague Dawley rats 10-16 weeks of age. The rats were maintained on a 12:12 h light:dark cycle with ad libitum access to food and water.

\section{Synthesis of KTI09}

A solution of 2-benzylpiperidine (500 mg, $2.85 \mathrm{mmol})$ in tetrahydrofuran (THF) $(25 \mathrm{~mL})$ was treated with diisopropylethylamine $(1.5 \mathrm{~mL}, 8.55 \mathrm{mmol})$ and triphosgene $(423 \mathrm{~g}$, $1.43 \mathrm{mmol}$ ), and the reaction mixture was stirred for $30 \mathrm{~min}$ at $4{ }^{\circ} \mathrm{C}$. The mixture was poured into water and extracted with ethyl acetate. The organic layer was washed with water and brine, dried over anhydrous magnesium sulfate, and concentrated under reduced pressure. The intermediate was dissolved in THF (30 mL), and diisopropylethylamine (1.5 mL, $8.55 \mathrm{mmol}$ ), 4-Dimethylaminopyridine (348 mg, $2.85 \mathrm{mmol}$ ), and 4-(4-bromophenyl)-1H-1,2,3-triazole (1) (639 mg, $2.85 \mathrm{mmol}$ ) were added to the solution. The mixture was stirred for $2 \mathrm{~h}$ at $60^{\circ} \mathrm{C}$ and poured into saturated aqueous $\mathrm{NH}_{4} \mathrm{Cl}$ solution. The mixture was extracted with ethyl acetate, washed with water, and dried over anhydrous magnesium sulfate. The crude mixture was purified by flash column on silica gel with ethyl acetate/hexane (1:5) as the eluent to give (2-benzylpiperidin-1-yl)carbonyl-4-(4-bromophenyl)1H-1,2,3-triazole (320 mg, 27\% yield) as a yellow solid: ${ }^{1} \mathrm{H}$ NMR (500 MHz, $\mathrm{CDCl}_{3}$ ) $\delta 1.69-1.88$ (m, $\left.5 \mathrm{H}\right), 1.91$ (br. s., $1 \mathrm{H}), 2.67$ (br. s., $1 \mathrm{H}), 3.06-3.30$ (m, $1 \mathrm{H}), 3.35$ (br. s., $1 \mathrm{H})$, 4.34 (d, J=13.1 Hz, 1 H), 4.82 (br. s., $1 \mathrm{H}), 6.83-7.07$ (m, 1 H), 7.08-7.31 (m, 5 H), 7.31-7.47 (m, 1 H), 7.57 (d, J=8.2 $\mathrm{Hz}, 2 \mathrm{H}), 7.65$ (bs, $2 \mathrm{H}$ ). The analytical data were consistent with literature values (Scheme 1). ${ }^{9}$

A solution of (2-benzylpiperidin-1-yl)carbonyl-4-(4bromophenyl)-1H-1,2,3-triazole (1) (850 mg, $2.0 \mathrm{mmol}$ ) in THF $(73 \mathrm{~mL})$ and water $(36 \mathrm{~mL})$ was treated with phenylboronic acid (488 mg, $4.0 \mathrm{mmol}$ ), $\mathrm{K}_{2} \mathrm{CO}_{3}(829 \mathrm{mg}, 6.0 \mathrm{mmol}$ ), and $\mathrm{PdCl}_{2}$ (dppf) $(55 \mathrm{mg}, 0.075 \mathrm{mmol})$, and the reaction mixture was stirred for $2 \mathrm{~h}$ at $80^{\circ} \mathrm{C}$ under $\mathrm{N}_{2}$. The mixture was poured into water and extracted with ethyl acetate. The organic layer was washed with water and dried over anhydrous magnesium sulfate. The crude mixture was purified by flash column on silica gel with ethyl acetate:hexane (1:4) as the eluent to give KT109 (709 mg, 84\%) as an off-white solid: ${ }^{1} \mathrm{H}$ NMR $\left(500 \mathrm{MHz}, \mathrm{CDCl}_{3}\right) \delta 1.63-1.85(\mathrm{~m}, 4 \mathrm{H})$, 1.85-2.09 (m, 3 H), 2.74 (bs, 1 H), 3.27 (br. s., 1 H), 3.40 


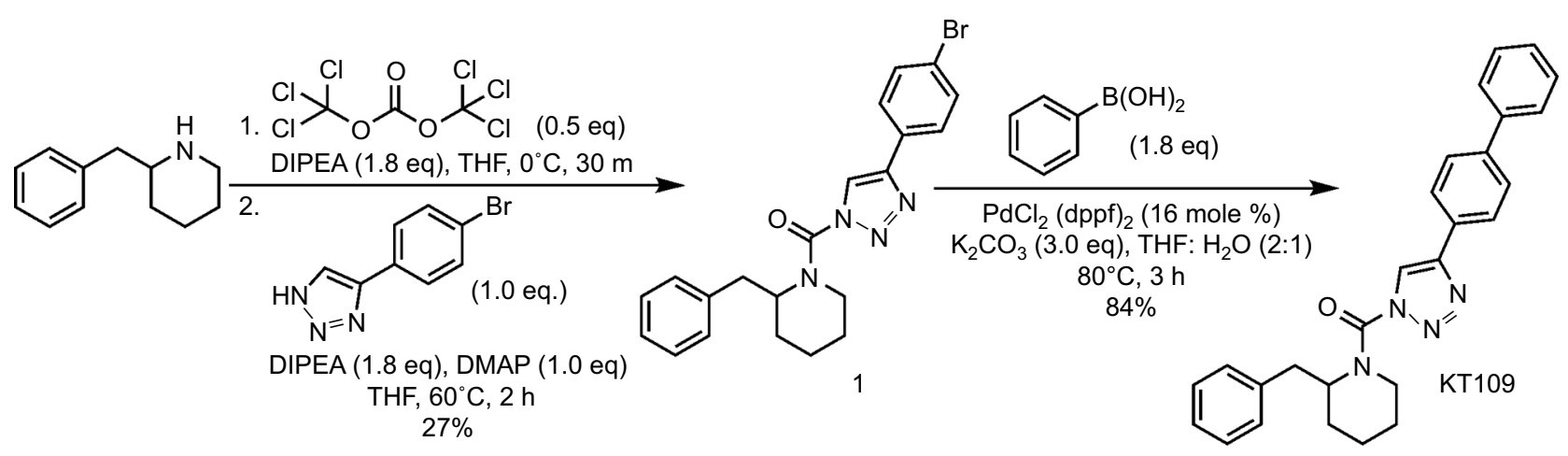

Scheme I Synthesis of KTI09.

Abbreviations: DIPEA: N,N-Diisopropylethylamine; THF, tetrahydrofuran; DMAP, 4-Dimethylaminopyridine; PdCl2 (dpPf)2: (I,I'-Bis(diphenylphosphino)ferrocene) palladium(II) dichloride; $\mathrm{K} 2 \mathrm{CO} 3$ : potassium carbonate

(bs, $1 \mathrm{H}), 4.40$ (d, J=13.4 Hz, $1 \mathrm{H}), 4.90$ (bs, $1 \mathrm{H}), 7.15-7.37$ (m, $4 \mathrm{H}), 7.37-7.44$ (m, 1 H), 7.44-7.58 (m, $2 \mathrm{H}), 7.62-7.79$ (m, $4 \mathrm{H}), 7.91$ (bs, $2 \mathrm{H})$. The analytical data were consistent with literature values. ${ }^{9}$

\section{Activity-based protein profiling (ABPP)}

HEK293 T cells (ATCC, Manassas, VA, USA) were transfected with pcDNA4 vector expressing rat DAGL $\beta$ (NM_001107120.1) or empty vector controls. Twenty-four hours later, the cells were lysed in activity buffer $(5 \mathrm{mM}$ $\mathrm{CaCl}_{2}, 100 \mathrm{mM} \mathrm{NaCl}, 50 \mathrm{mM}$ HEPES, $\mathrm{pH}$ 7) and diluted to a concentration of $1 \mathrm{mg} / \mathrm{mL}$. The proteomes were incubated with KT109 or DMSO $(<0.5 \%)$ for $30 \mathrm{~min}$ at room temperature. The samples were subsequently treated with the selective active site directed fluorescent probe, $1 \mu \mathrm{M}$ HT- 01 , for $30 \mathrm{~min}$ at $37^{\circ} \mathrm{C}$. The reactions were quenched with sodium dodecyl sulfate polyacrylamide gel electrophoresis (SDS-PAGE) sample loading buffer, heated at $95^{\circ} \mathrm{C}$ for 5 min, and subsequently separated by SDS-PAGE. The gels were fixed by incubating twice with water:methanol:acetic acid (50:40:10, v:v) for 15 min each and subsequently washed in $\mathrm{H}_{2} \mathrm{O}$ for $15 \mathrm{~min}$. The gels were visualized on a GE Typhoon FLA 7000 fluorescent gel scanner. For ABPP of rat tissues, the animals received an intraperitoneal (IP) injection of $30 \mathrm{mg} / \mathrm{kg} \mathrm{KT} 109$ or vehicle $1 \mathrm{~h}$ before plantar incision, and tissues were harvested $4 \mathrm{~h}$ after incision. The tissues were homogenized in activity buffer, treated with 1 $\mu \mathrm{M}$ HT-01 as above, separated by SDS-PAGE, and visualized on the gel scanner.

\section{Plantar incision}

Rats were subjected to plantar incision of the hind paw, a well-characterized model of postsurgical pain. ${ }^{5}$ Surgeries were performed under $2 \%-2.5 \%$ isoflurane anesthesia delivered in $\mathrm{O}_{2}$ via a snout mask. The animals were maintained normothermic during the surgical procedure using a heating pad. The heel was sterilized with $70 \%$ ethanol followed by betadine solution and a $1 \mathrm{~cm}$ longitudinal incision was made through the skin and fascia of the plantar surface of the right hind paw beginning $\sim 0.5 \mathrm{~cm}$ from the heel. The plantaris muscle was lifted and longitudinally transected, and the wound closed with two prolene mattress sutures. The wound was subsequently cleaned with $70 \%$ ethanol and an antibiotic ointment was applied. Sham procedures consisted of anesthesia and disinfection of the hind paw, but without incision. KT109, ketoprofen, or vehicle (DMSO) was injected $1 \mathrm{~h}$ prior to surgery via the IP route in a volume of $1 \mu \mathrm{L} / \mathrm{g}$ body weight.

\section{Lipid quantification}

Rats were anesthetized with isoflurane and decapitated with a small animal guillotine. The lumbar spinal cords (LSCs) and heels of each hind paw were removed and flash frozen on dry ice and stored at $-80^{\circ} \mathrm{C}$. Endocannabinoid quantification was performed as described. ${ }^{25}$ Briefly, the tissues were weighed and homogenized using a bead beater in $8 \mathrm{~mL}$ of 2:1:1 chloroform:methanol:Tris $(50 \mathrm{mM}, \mathrm{pH})$ in the presence of $40 \mathrm{ng} \mathrm{d}_{5}-2-\mathrm{AG}, 20 \mathrm{ng} \mathrm{d}_{4}-\mathrm{PGE}_{2}$, and $200 \mathrm{~d}_{8}$-AA. Following centrifugation at $4{ }^{\circ} \mathrm{C}$, the organic layer was removed and the sample was extracted again. The resulting combined organic layer was dried down with argon and redissolved in $120 \mu \mathrm{L}$ of 2:1 chloroform:methanol for endocannabinoid quantification or $120 \mu \mathrm{L} 40 \%$ acetonitrile in water $(\mathrm{v}: \mathrm{v})$ for $\mathrm{PGE}_{2}$ and $\mathrm{AA}$ quantification, and $10 \mu \mathrm{L}$ of each sample was injected into a Thermo Fisher Scientific TSQ Quantum Access Triple Quadropole mass spectrometer in triplicate. The parameters for the endocannabinoid quantification were as described. ${ }^{25} \mathrm{AA}$ and $\mathrm{PGE}_{2}$ analysis was performed on a Thermo Fisher Scientific 3000 HPLC system equipped with a Luna C18 column $(150 \times 2 \mathrm{~mm})$ coupled to the electrospray 
ionization source of a Thermo Fisher Scientific TSQ Quantum Access triple quadrupole mass spectrometer. Separation was performed with a linear gradient of buffer $\mathrm{A}\left(\mathrm{H}_{2} \mathrm{O}\right)$ and buffer B (acetonitrile) starting with $40 \%$ buffer B followed by an increase to $90 \%$ buffer B in 20 min with a flow rate at $200 \mu \mathrm{L} / \mathrm{min}$. The mass spectrometer was operated in the negative ion mode with a high voltage set to $-3.0 \mathrm{kV}$, sheath gas pressure at $50 \mathrm{AU}$, and a capillary temperature of $350^{\circ} \mathrm{C}$. The collision cell was operated at 1.5 mTorr Argon. The collision energy varied depending on the compound. Each transition was monitored at a $100 \mathrm{~ms}$ dwell time during the course of the experiment.

\section{Mechanical hyperalgesia}

Rats were habituated to the testing room for 1 week. An electronic von Frey anesthesiometer (IITC Life Sciences, Woodland Hills, CA, USA) was applied with increasing static pressure to the plantar surface of the hind paw or heel until the animals lifted the hind paw as previously described. ${ }^{12}$ The number of grams of force applied by the probe to induce withdrawal was recorded. Five recordings were obtained on each hind paw with at least 2 min between measurements.

\section{Incapacitance}

An incapacitance meter (IITC Life Sciences) was used to measure hind limb weight bearing. The animals were first conditioned to the apparatus each day for up to 1 week prior to the baseline measurements. Postsurgical measurements were obtained $4 \mathrm{~h}$ after surgery. At least seven weight-bearing measurements were obtained and, after disregarding the highest and lowest values, the trimmed means were expressed as the mean differences $(\mathrm{g})$ between the left and right hind paws.

\section{Measurement of postsurgical locomotor activity}

Rats were maintained in their home cages and were placed in the PAS Home Cage apparatus (San Diego Instruments, San Diego, CA, USA) to measure mobility and rearing behavior before and after surgery. Each cage was surrounded by a $4 \times 8$ photobeam array that detected and recorded movements in the $\mathrm{X} / \mathrm{Y}$ direction, as well as an eight-beam rearing frame that detected rearing (vertical, Z-axis) events. The animals were first conditioned for several days in the same cages in the testing room to avoid novelty-induced changes in locomotor activity. To obtain baseline (presurgical) data, the animals were injected with KT109, ketoprofen, or vehicle $1.5 \mathrm{~h}$ prior to the onset of the dark cycle. The locomotor data were obtained during the subsequent $12 \mathrm{~h}$ dark period. The same procedure was used to obtain the postsurgical data. Specifically, rats received an injection of drug or vehicle, underwent plantar incision $1 \mathrm{~h}$ later, and were returned to their home cages prior to the beginning of the dark cycle.

\section{Statistical analysis}

Data are presented as mean \pm SE. Unpaired $t$-test or one-way analysis of variance followed by Tukey's or Dunnett's post hoc tests, as appropriate, were used to determine significance of differences between means. We considered $p$ values $<0.05$ as significant.

\section{Results}

\section{KTI09 is a systemically active DAGL $\beta$ inhibitor in rats}

KT109 is a selective and irreversible DAGL $\beta$ inhibitor that does not inhibit the related enzyme DAGL $\alpha$ in mice. ${ }^{21}$ To determine whether KT109 inhibits rat DAGL $\beta$, we performed ABPP of DAGL $\beta$ inhibition using the active site probe HT- $01 .{ }^{21}$ In ABPP, active enzymes are labeled by a fluorescent active site-directed probe, which allows visualization of enzyme activities and their inhibition in vitro and ex vivo. ${ }^{32,35}$ Consequently, enzymes treated with inhibitors exhibit reduced labeling by the active site probe. ABPP demonstrated that KT109 dose dependently inhibited DAGL $\beta$ activity in vitro (Figure 1A), confirming that this inhibitor is suitable to probe the activity of rat DAGL $\beta$. HT- 01 also labeled a nonspecific breakdown product of DAGL $\beta$ that was similarly inhibited by KT109 (Figure 1A), as reported previously in mice. ${ }^{21}$ In mice, KT109 maintains selectivity for DAGL $\beta$ at a dose of $30 \mathrm{mg} / \mathrm{kg} .{ }^{21,46} \mathrm{To}$ determine whether KT109 inhibits rat DAGL $\beta$ in vivo, we performed ABPP on brains and LSCs of rats treated with KT109 (30 mg/kg, IP) or vehicle. KT109 inhibited both brain and LSC DAGL $\beta$ (Figure 1B). In the brain, KT109 also inhibited the unrelated enzyme alpha/beta-hydrolase domain containing 6 (ABHD6) (Figure 1B), as previously reported in mice..$^{21}$ Importantly, although ABHD6 can hydrolyze 2-AG to generate AA, it does not contribute significantly to eicosanoid levels in various tissues and its inhibition does not produce antinociceptive effects. ${ }^{21,46}$ We subsequently determined whether DAGL $\beta$ inhibition alters 2-AG, $\mathrm{AA}$, and $\mathrm{PGE}_{2}$ levels in rats. In mice, DAGL $\beta$ inhibition reduces basal levels of $2-A G$ and AA in the liver, but not brain. ${ }^{21,45}$ Our results similarly revealed that KT109 reduced the liver levels, but not brain levels of 2-AG and AA (Figure 2), despite sufficient penetration of the inhibitor in the brain as demonstrated by our ABPP analysis (Figure 1). Furthermore, we also demonstrate that 


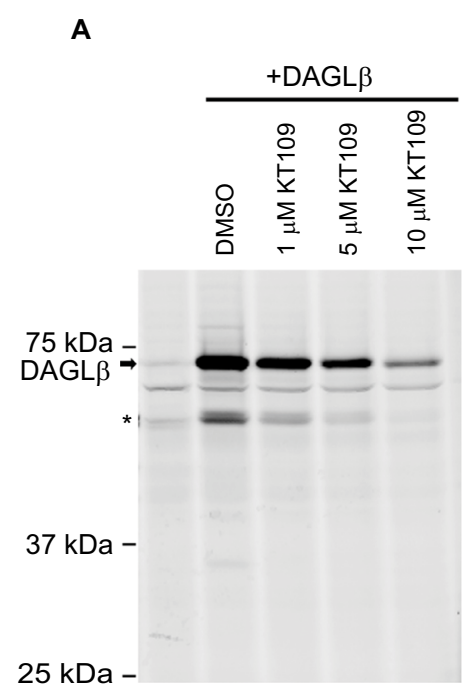

B
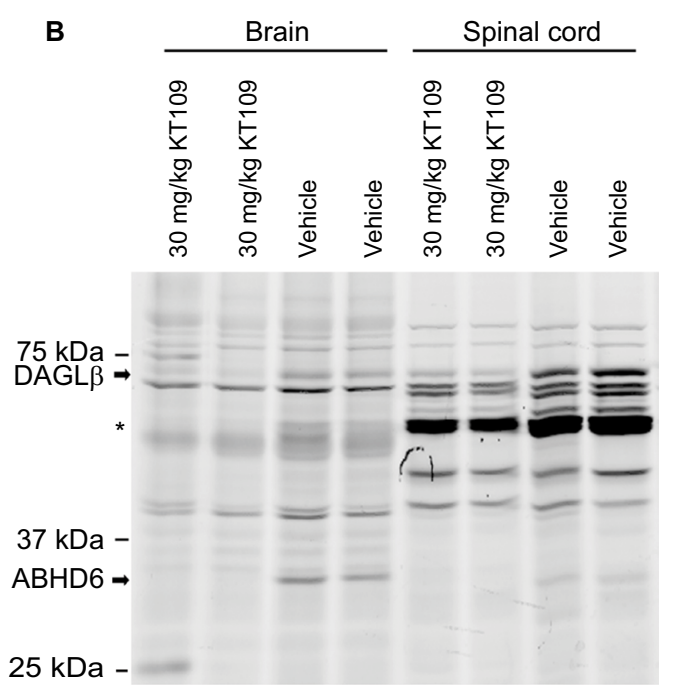

Figure I KTI09 inhibits rat DAGL $\beta$ in vitro and in vivo.

Notes: (A) HEK293T cells expressing DAGL $\beta$ were incubated with KTI09 or DMSO for $60 \mathrm{~min}$ at $25^{\circ} \mathrm{C}$ and subsequently probed with I $\mu$ M HT-0I. The first lane represents empty vector transfected HEK293T cells, while the next four lanes show cells expressing DAGL $\beta$. The HT-0I-labeled proteins in the gels were visualized by ingel fluorescence. (B) Rats were injected with KTI09 (30 mg/kg, IP) or vehicle I h prior to plantar incision. Brains and LSCs were harvested $4 \mathrm{~h}$ later and subjected to ABPP using HT-OI. The bands corresponding to DAGL $\beta$ are indicated. *Indicates the known DAGL $\beta$ degradation product(s).

Abbreviations: ABHD6, alpha/beta-hydrolase domain containing 6; ABPP, activity-based protein profiling; DAGL $\beta$, diacylglycerol lipase $\beta$; DMSO, dimethylsulfoxide; IP, intraperitoneal; LSCs, lumbar spinal cords.

A
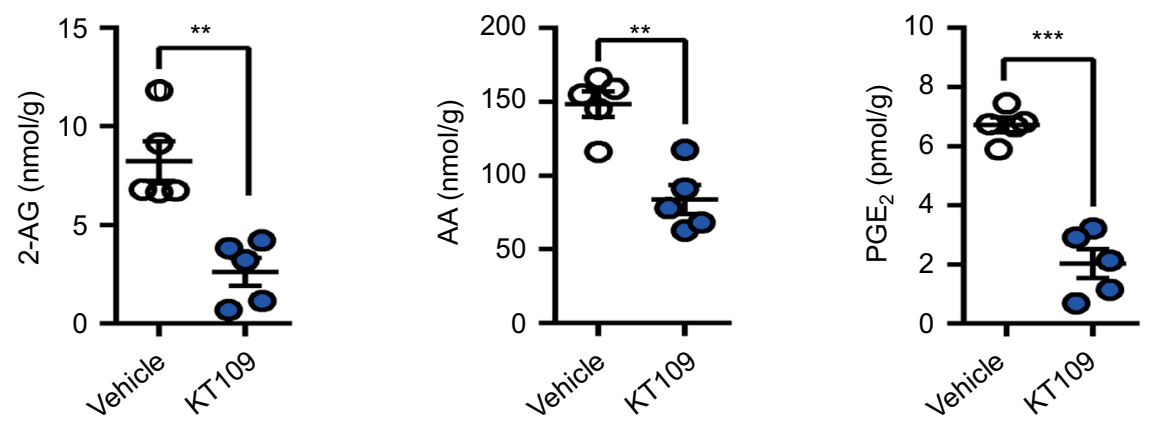

B
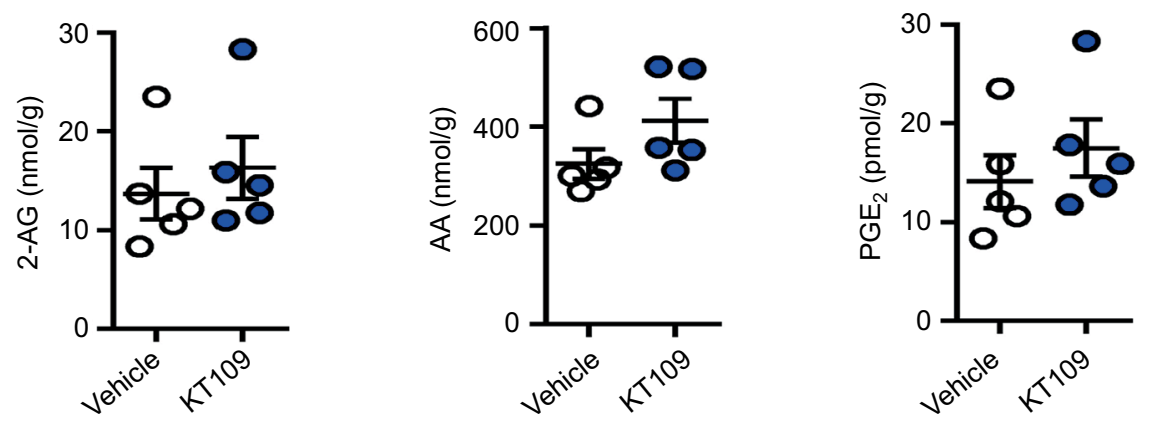

Figure $2 \mathrm{KTI} 09$ reduces the levels of 2-AG and downstream metabolites in the liver, but not brain.

Notes: Levels of 2-AG, AA, and PGE2 in (A) liver and (B) brain $4 \mathrm{~h}$ after KTI09 $(30 \mathrm{mg} / \mathrm{kg}$, IP) or vehicle administration. **p $<0.01$; $* * * p<0.00 \mathrm{I}$. Abbreviations: 2-AG, 2-arachidonoylglycerol; AA, arachidonic acid; IP, intraperitoneal; PGE2, prostaglandin E2. 
KT109 treatment suppresses PGE $_{2}$ production in the liver (Figure 2A). Collectively, these results indicate that KT109 is a systemically active central nervous system penetrant DAGL $\beta$ inhibitor in rats.

\section{Effects of DAGL $\beta$ inhibition upon postoperative $\mathrm{PGE}_{2}$ production}

Plantar incision induces an increase in $\mathrm{PGE}_{2}$ levels at the surgical site and spinal cord, and inhibition of COX enzymes reduces $\mathrm{PGE}_{2}$ production and pain. ${ }^{28,34,49}$ Because incisional pain and analgesic responses are similar between the genders in Sprague Dawley rats, we conducted our studies only in male rats. ${ }^{27}$ We quantified $\mathrm{PGE}_{2}$ levels at the surgical site and LSC $4 \mathrm{~h}$ after plantar incision and observed an increase in $\mathrm{PGE}_{2}$ production at both sites (Figure 3). Similarly, 2-AG levels were increased in LSC after surgery, while the levels at the surgical site were unaffected. While treatment of rats with KT109 did not alter the levels of 2-AG or AA at either site, KT109 modestly but significantly reduced $\mathrm{PGE}_{2}$ levels in the LSC after surgery (Figure 3B). In contrast to KT109, administration of the general COX1/2 inhibitor ketoprofen ( $10 \mathrm{mg} / \mathrm{kg}$, IP) highly suppressed $\mathrm{PGE}_{2}$ production within the surgical site and LSC after surgery (Figure 3).

\section{Effect of DAGL $\beta$ inhibition upon postoperative pain}

To explore the effect of DAGL $\beta$ inhibition upon postoperative pain, we measured mechanical hyperalgesia (evoked response), incapacitance/weight bearing (functional response), and home cage locomotor activity (functional/ spontaneous response) before and after surgery. Mechanical hyperalgesia was examined in the ventral plantar aspect of the paw as well as in the area proximal to the incision site in the heel. In vehicle-treated rats, incision resulted in a significant decrease in mechanical thresholds at both sites (Figure 4A). Treatment of rats with KT109 or ketoprofen did not alter the mechanical thresholds at either site, consistent with previous work using clinically efficacious COX inhibitors, suggesting that the measurement of evoked responses such as paw withdrawal thresholds may not be predictive of the clinical efficacy of candidate analgesics. ${ }^{38,42}$ Consequently, we

A
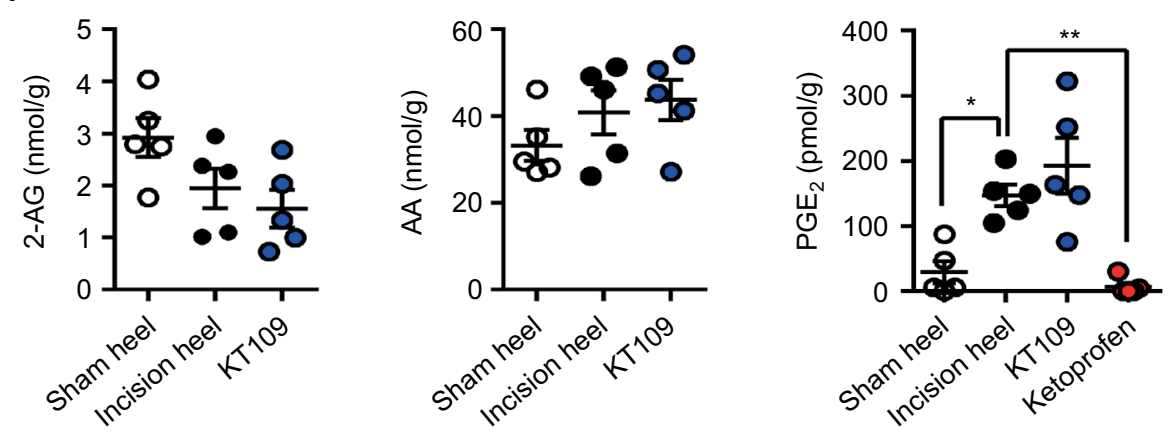

B
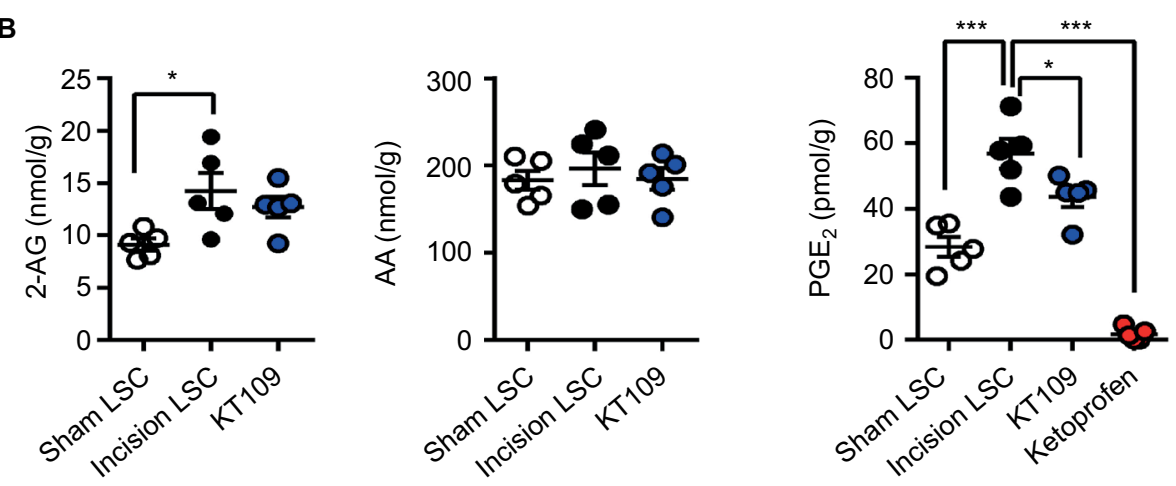

Figure 3 Effects of KTI09 and ketoprofen upon postsurgical PGE, levels.

Notes: (A) Levels of 2-AG, AA, and PGE in the heels of rats $4 \mathrm{~h}$ after plantar incision after treatment with $30 \mathrm{mg} / \mathrm{kg} \mathrm{KT} 109,10 \mathrm{mg} / \mathrm{kg}$ ketoprofen, or vehicle (denoted as incision heel). Sham rats were injected with vehicle; they underwent a sham incision and their heels were harvested $4 \mathrm{~h}$ later. (B) 2-AG, AA, and PGE 2 levels in LSC $4 \mathrm{~h}$ after surgery in vehicle-, KTI09-, or ketoprofen-treated rats. ${ }^{*} p<0.05 ; * *_{p}<0.01$; $* * * 0<0.001$.

Abbreviations: 2-AG, 2-arachidonoylglycerol; AA, arachidonic acid; LSC, lumbar spinal cord; PGE2, prostaglandin E2. 

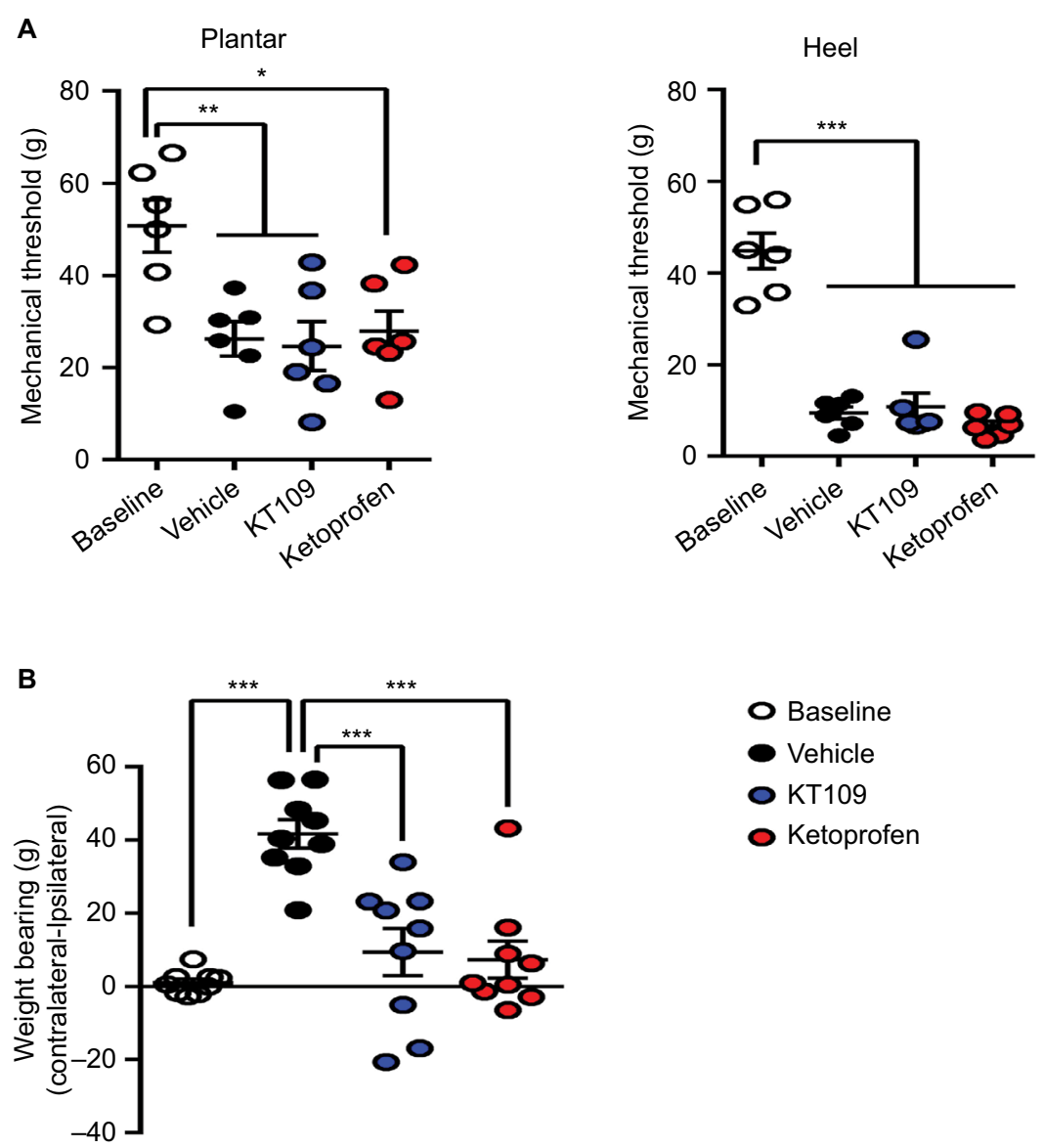

Figure 4 Mechanical hyperalgesia and incapacitance in rats after plantar incision.

Notes: (A) Mechanical thresholds $(\mathrm{g})$ in the heel and plantar aspect of the paw at baseline and $4 \mathrm{~h}$ after plantar incision in rats treated with vehicle, $30 \mathrm{mg} / \mathrm{kg} \mathrm{KTI} 09$, or $10 \mathrm{mg} / \mathrm{kg}$ ketoprofen. (B) Hind limb weight bearing (differences in $\mathrm{g}$ ) at baseline and $4 \mathrm{~h}$ after plantar incision in rats treated with vehicle, $30 \mathrm{mg} / \mathrm{kg} \mathrm{KTI09,} \mathrm{or} 10 \mathrm{mg} / \mathrm{kg}$ ketoprofen. $* p<0.05 ; * * p<0.01 ; * * * p<0.001$.

employed incapacitance/weight bearing and home cage activity as non-evoked functional measures of postsurgical pain/ disability. As expected, plantar incision induced a significant weight-bearing differential in vehicle-treated rats such that the animals placed more weight on the contralateral uninjured hind limb (Figure 4B). In contrast to their lack of efficacy in the evoked mechanical hyperalgesia measurements, treatment with $30 \mathrm{mg} / \mathrm{kg} \mathrm{KT} 109$ or $10 \mathrm{mg} / \mathrm{kg}$ ketoprofen significantly reduced the postsurgical weight-bearing differential, which returned to the presurgical baseline (Figure 4B).

We also employed home cage locomotor activity over the $12 \mathrm{~h}$ dark phase period as a readout of postsurgical pain. KT109 and ketoprofen did not alter the locomotor activity or rearing at baseline (Figure 5A, B). Consistent with previous work, plantar incision induced a significant reduction in locomotor activity $(p=0.0001)$ and rearing $(p=0.0019)$ in vehicle-treated rats. ${ }^{28}$ Treatment of rats with $30 \mathrm{mg} / \mathrm{kg}$ KT109 did not alter the reduction of locomotor activity observed after surgery (Figure 5A, B). Surprisingly, the clinically efficacious analgesic ketoprofen likewise did not alter postsurgical locomotor activity (Figure 5A, B). The analgesic effects of ketoprofen persisted for only $\sim 5 \mathrm{~h}$ in rats, which we hypothesized may explain its lack of efficacy in modulating the locomotor activity over the $12 \mathrm{~h}$ time course of the study. ${ }^{16}$ Indeed, when locomotor activity was examined during the first $6 \mathrm{~h}$ after surgery, ketoprofen-treated rats demonstrated an increase in postsurgical locomotion (Figure 5C, D). In contrast, locomotor activity in KT109-treated rats was similar to the vehicle-treated group.

\section{Discussion}

DAGL $\beta$ is expressed in peripheral immune cells and in microglia in the central nervous system, and its activity contributes to eicosanoid production during inflammation in vitro and in vivo. ${ }^{21,45,46}$ DAGL $\beta$ inhibition produces antinociceptive effects in models of inflammatory pain in mice. ${ }^{46}$ We recently reported that $2-A G$ levels were increased in the cerebrospinal and synovial fluid of patients undergoing total knee arthroplasty and its levels correlated with the severity of acute postoperative pain, suggesting that conversion of 


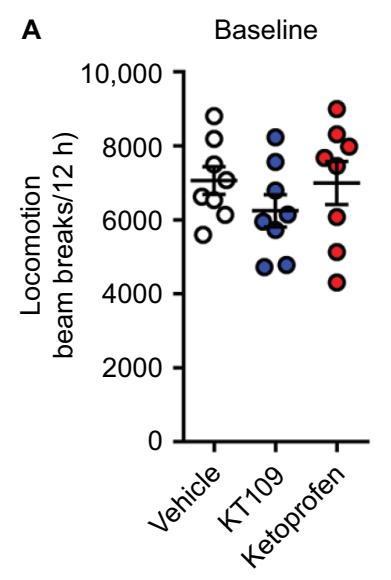

C

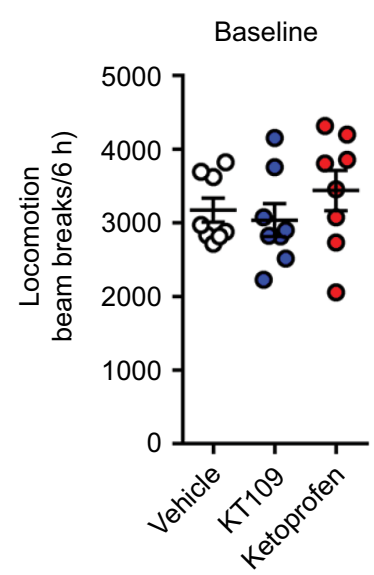

Incision
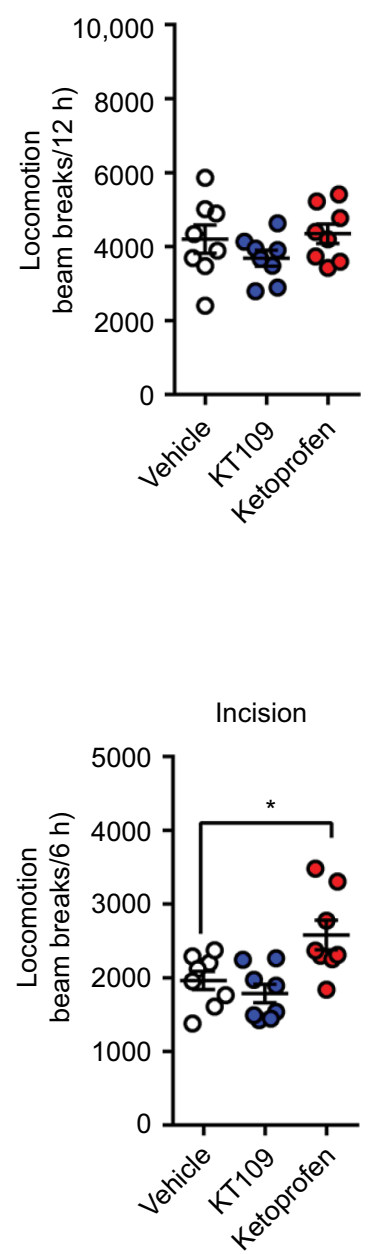

B

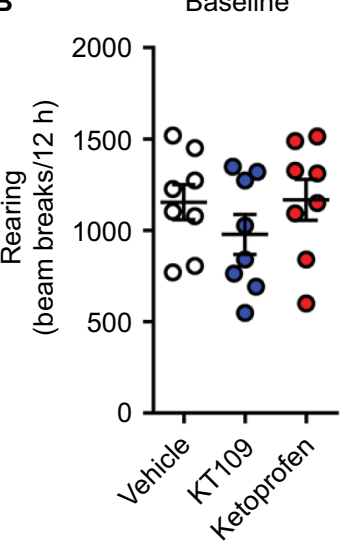

D

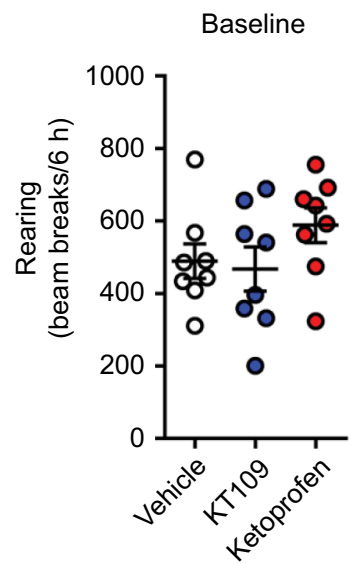

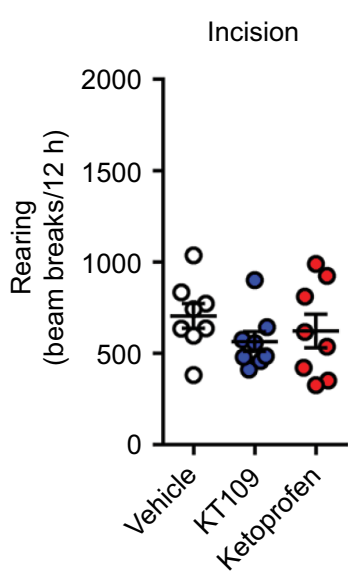

Incision

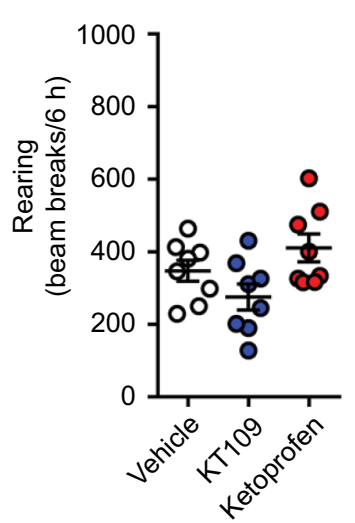

Figure 5 Home cage locomotor activity and rearing before and after plantar incision.

Notes: (A) Locomotor activity and (B) rearing over $12 \mathrm{~h}$ at baseline and after plantar incision in rats treated with vehicle, $30 \mathrm{mg} / \mathrm{kg} \mathrm{KTI09,} \mathrm{or} 10 \mathrm{mg} / \mathrm{kg}$ ketoprofen. (C) Locomotion and (D) rearing over the first $6 \mathrm{~h}$ after plantar incision or at baseline in rats treated with vehicle, $30 \mathrm{mg} / \mathrm{kg} \mathrm{KTI09,} \mathrm{or} 10 \mathrm{mg} / \mathrm{kg} \mathrm{ketoprofen}$. In each case, the left panel represents the baseline condition while the right panel represents incision. $* p<0.05$.

2-AG into downstream eicosanoids could contribute to pain during the postoperative period. ${ }^{1}$

The preclinical results obtained in this study demonstrate that DAGL $\beta$ inhibition modestly reduces postoperative $\mathrm{PGE}_{2}$ production in the LSC, but does not affect $\mathrm{PGE}_{2}$ levels at the surgical site. DAGL $\beta$ inhibition also did not alter 2-AG levels at either site, indicating that any analgesic effects observed following KT109 administration likely stem from reduction in $\mathrm{PGE}_{2}$ levels rather than 2-AG-mediated activation of cannabinoid receptors. In contrast to KT109, COX inhibition by ketoprofen highly suppressed $\mathrm{PGE}_{2}$ production at both anatomic sites. This is relevant because in the clinical setting, COX inhibitors reduce pain peripherally (i.e., when infiltrated into the surgical site) as well as centrally. ${ }^{6,29,30} \mathrm{We}$ examined the antinociceptive effects of DAGL $\beta$ inhibition using three complementary behavioral assays. Mechanical hyperalgesia is an evoked measure of mechanical sensitivity, and our data indicate a significant reduction in mechanical thresholds after plantar incision, consistent with previous work. ${ }^{5}$ However, COX and DAGL $\beta$ inhibition did not rescue the surgically induced decrease in withdrawal thresholds, as was observed by others using clinically efficacious COX inhibitors. ${ }^{42}$ This suggests that evoked measurements of mechanical sensitivity may not be predictive of the clinical efficacy of candidate analgesics, at least in the incision model of postoperative pain. Consequently, we employed two non-evoked measures of pain/disability. In the incapacitance model, both KT109 and ketoprofen reversed the weight-bearing imbalance induced by incision, a surprising result in the case of KT109 due to its modest effects upon spinal $\mathrm{PGE}_{2}$ levels. This may suggest that incapacitance, a measure of static weight bearing, may be sensitive to weak analgesics as observed by others. ${ }^{23}$

Acute postoperative pain manifests as ongoing/spontaneous pain at rest and pain upon ambulation, and time to ambulation is a clinically relevant measure of effective postoperative pain control. .3,39,47,48 We employed postsurgical locomotor 
activity as a readout of spontaneous, non-evoked pain because similar to humans, postsurgical pain in rodents is associated with reduced mobility (locomotion and rearing). ${ }^{4,7,28,34}$ In our hands, the clinically efficacious analgesic ketoprofen partially rescued the incision-induced decrease in locomotor activity, indicative of analgesia. In contrast, KT109 failed to alter postsurgical locomotor or rearing activity, which reflects its modest effects upon postsurgical $\mathrm{PGE}_{2}$ levels and weak analgesic effects. In addition to COX inhibitors, opioids are routinely employed as perioperative analgesics. As the main focus of our study was upon the 2-AG eicosanoid pathway, we compared the efficacy of KT109 against ketoprofen rather than clinically efficacious opioid analgesics such as morphine.

The lack of efficacy of KT109 contrasts the antinociceptive effects observed with this compound in models of inflammatory pain. ${ }^{46}$ One possible explanation for this discrepancy may reflect differences in the severity of the injury and resulting pain. Indeed, acute postoperative pain is reflected by reduced locomotor activity in rodents, indicative of significant ongoing pain, while this is not observed in models of inflammatory pain. ${ }^{44}$ In the inflammatory pain model, KT109 produced its effects solely through a peripheral mechanism at the site of inflammation, while COX inhibitors exerted their analgesic effects at the peripheral and central sites, which may further account for their greater efficacy. ${ }^{6,7,29,30}$ Although DAGL $\alpha$ is the main enzyme that regulates 2-AG levels in the spinal cord and its inhibition could reduce spinal eicosanoid production, global inhibition of this enzyme leads to enhanced anxiety by dampening 2-AG signaling at the brain cannabinoid receptor 1 and may, in fact, enhance pain, indicating that this enzyme is unlikely to be a suitable target for the development of systemically active analgesics. ${ }^{13,18,24,40,43}$ Our study shows that DAGL $\beta$ contributes to $\mathrm{PGE}_{2}$ production in the liver, but not in the brain, or at the incision site after surgery, and that it makes only a minor contribution to the postsurgical rise in $\mathrm{PGE}_{2}$ in the LSC. These results are in line with the inconsistent efficacy of KT109 as a postsurgical analgesic across multiple different measures of pain.

\section{Conclusion}

Our study provides evidence that DAGL $\beta$ activity does not substantially contribute to postoperative $\mathrm{PGE}_{2}$ production and indicates that this enzyme is not a suitable target for the development of analgesics to treat acute postoperative pain that are superior to those already available. Nevertheless, inhibitors targeting this enzyme may be useful for the treatment of pain associated with other conditions.

\section{Acknowledgment}

We would like to thank Robert Rieger at the Stony Brook University Proteomics Center for help with mass spectrometry.

\section{Disclosure}

The authors report no conflicts of interest in this work.

\section{References}

1. Azim S, Nicholson J, Rebecchi MJ, et al. Endocannabinoids and acute pain after total knee arthroplasty. Pain. 2015;156(2):341-347.

2. Baratta JL, Gandhi K, Viscusi ER. Perioperative pain management for total knee arthroplasty. J Surg Orthop Adv. 2014;23(1):22-36.

3. Booker L, Kinsey SG, Abdullah RA, et al. The fatty acid amide hydrolase (FAAH) inhibitor PF-3845 acts in the nervous system to reverse LPS-induced tactile allodynia in mice. Br J Pharmacol. 2012;165(8):2485-2496.

4. Bree D, Moriarty O, O'Mahony CM, et al. Development and characterization of a novel, anatomically relevant rat model of acute postoperative pain. J Pain. 2015;16(5):421-435 e421-426.

5. Brennan TJ, Vandermeulen EP, Gebhart GF. Characterization of a rat model of incisional pain. Pain. 1996;64(3):493-501.

6. Buvanendran A, Kroin JS, Berger RA, et al. Upregulation of prostaglandin E2 and interleukins in the central nervous system and peripheral tissue during and after surgery in humans. Anesthesiology. 2006;104(3):403-410.

7. Buvanendran A, Kroin JS, Kari MR, Tuman KJ. A new knee surgery model in rats to evaluate functional measures of postoperative pain. Anesth Analg. 2008;107(1):300-308.

8. Buvanendran A, Kroin JS, Tuman KJ, et al. Effects of perioperative administration of a selective cyclooxygenase 2 inhibitor on pain management and recovery of function after knee replacement: a randomized controlled trial. JAMA. 2003;290(18):2411-2418.

9. Chang JW, Cognetta AB 3rd, Niphakis MJ, Cravatt BF. Proteomewide reactivity profiling identifies diverse carbamate chemotypes tuned for serine hydrolase inhibition. ACS Chem Biol. 2013;18(7): 1590-1599.

10. Eisenach JC, Curry R, Rauck R, Pan P, Yaksh TL. Role of spinal cyclooxygenase in human postoperative and chronic pain. Anesthesiology. 2010;112(5):1225-1233.

11. Fecho K, Jackson F, Smith F, Overdyk FJ. In-hospital resuscitation: opioids and other factors influencing survival. Ther Clin Risk Manag. 2009;5:961-968.

12. Galbavy W, Kaczocha M, Puopolo M, Liu L, Rebecchi MJ. Neuroimmune and neuropathic responses of spinal cord and dorsal root ganglia in middle age. PLoS One. 2015;10(8):e0134394.

13. Gao Y, Vasilyev DV, Goncalves MB, et al. Loss of retrograde endocannabinoid signaling and reduced adult neurogenesis in diacylglycerol lipase knock-out mice. J Neurosci. 2010;30(6):2017-2024.

14. Garg AX, Kurz A, Sessler DI, et al; POISE-2 Investigators. Perioperative aspirin and clonidine and risk of acute kidney injury: a randomized clinical trial. JAMA. 2014;312(21):2254-2264.

15. Gerbershagen HJ, Aduckathil S, van Wijck AJ, Peelen LM, Kalkman CJ, Meissner W. Pain intensity on the first day after surgery: a prospective cohort study comparing 179 surgical procedures. Anesthesiology. 2013;118(4):934-944.

16. Girard P, Verniers D, Coppe MC, Pansart Y, Gillardin JM. Nefopam and ketoprofen synergy in rodent models of antinociception. Eur $J$ Pharmacol. 2008;584(2-3):263-271.

17. Gordon SM, Brahim JS, Rowan J, Kent A, Dionne RA. Peripheral prostanoid levels and nonsteroidal anti-inflammatory drug analgesia: replicate clinical trials in a tissue injury model. Clin Pharmacol Ther. 2002;72(2):175-183. 
18. Gregg LC, Jung KM, Spradley JM, et al. Activation of type 5 metabotropic glutamate receptors and diacylglycerol lipase-alpha initiates 2-arachidonoylglycerol formation and endocannabinoid-mediated analgesia. J Neurosci. 2012;32(28):9457-9468.

19. Hakkarainen TW, Steele SR, Bastaworous A, et al. Nonsteroidal antiinflammatory drugs and the risk for anastomotic failure: a report from Washington State's Surgical Care and Outcomes Assessment Program (SCOAP). JAMA Surg. 2015;150(3):223-228.

20. Hastings S, Myles P, McIlroy D. Aspirin and coronary artery surgery: a systematic review and meta-analysis. Br JAnaesth. 2015;115(3):376-385.

21. Hsu KL, Tsuboi K, Adibekian A, Pugh H, Masuda K, Cravatt BF. DAGLbeta inhibition perturbs a lipid network involved in macrophage inflammatory responses. Nat Chem Biol. 2012;8(12):999-1007.

22. Ignatowska-Jankowska B, Wilkerson JL, Mustafa M, et al. Selective monoacylglycerol lipase inhibitors: antinociceptive versus cannabimimetic effects in mice. J Pharmacol Exp Ther. 2015;353(2):424-432.

23. Ishikawa G, Nagakura Y, Takeshita N, Shimizu Y. Efficacy of drugs with different mechanisms of action in relieving spontaneous pain at rest and during movement in a rat model of osteoarthritis. Eur J Pharmacol. 2014;738:111-117.

24. Jenniches I, Ternes S, Albayram O, et al. Anxiety, stress, and fear response in mice with reduced endocannabinoid levels. Biol Psychiatry. 2015;79(10):858-868.

25. Kaczocha M, Rebecchi MJ, Ralph BP, et al. Inhibition of fatty acid binding proteins elevates brain anandamide levels and produces analgesia. PLoS One. 2014;9(4):e94200.

26. Kharasch ED, Brunt LM. Perioperative opioids and public health. Anesthesiology. 2016;124(4):960-965.

27. Kroin JS, Buvanendran A, Nagalla SK, Tuman KJ. Postoperative pain and analgesic responses are similar in male and female Sprague-Dawley rats. Can J Anaesth. 2003;50(9):904-908.

28. Kroin JS, Buvanendran A, Watts DE, Saha C, Tuman KJ. Upregulation of cerebrospinal fluid and peripheral prostaglandin E2 in a rat postoperative pain model. Anesth Analg. 2006;103(2):334-343.

29. Kurosaka K, Tsukada S, Seino D, Morooka T, Nakayama H, Yoshiya $\mathrm{S}$. Local infiltration analgesia versus continuous femoral nerve block in pain relief after total knee arthroplasty: a Randomized Controlled Trial. J Arthroplasty. 2016;31(4):913-917.

30. Lavand'homme PM, Roelants F, Waterloos H, De Kock MF. Postoperative analgesic effects of continuous wound infiltration with diclofenac after elective cesarean delivery. Anesthesiology. 2007;106(6): $1220-1225$

31. Liu X, Zhao X, Lou J, Wang Y, Shen X. Parecoxib added to ropivacaine prolongs duration of axillary brachial plexus blockade and relieves postoperative pain. Clin Orthop Relat Res. 2013;471(2):562-568.

32. Liu Y, Patricelli MP, Cravatt BF. Activity-based protein profiling: the serine hydrolases. Proc Natl Acad Sci U SA. 1999;96(26):14694-14699.

33. Lunn TH, Husted H, Laursen MB, Hansen LT, Kehlet H. Analgesic and sedative effects of perioperative gabapentin in total knee arthroplasty: a randomized, double-blind, placebo-controlled dose-finding study. Pain. 2015;156(12):2438-2448.
34. Martin TJ, Zhang Y, Buechler N, Conklin DR, Eisenach JC. Intrathecal morphine and ketorolac analgesia after surgery: comparison of spontaneous and elicited responses in rats. Pain. 2005;113(3):376-385.

35. Nomura DK, Dix MM, Cravatt BF. Activity-based protein profiling for biochemical pathway discovery in cancer. Nat Rev Cancer. 2010;10(9):630-638.

36. Nomura DK, Morrison BE, Blankman JL, et al. Endocannabinoid hydrolysis generates brain prostaglandins that promote neuroinflammation. Science. 2011;334(6057):809-813.

37. Pacher P, Kunos G. Modulating the endocannabinoid system in human health and disease-successes and failures. FEBS J. 2013;280(9): 1918-1943.

38. Percie du Sert N, Rice AS. Improving the translation of analgesic drugs to the clinic: animal models of neuropathic pain. $\mathrm{Br} J$ Pharmacol. 2014;171(12):2951-2963.

39. Perlas A, Kirkham KR, Billing R, et al. The impact of analgesic modality on early ambulation following total knee arthroplasty. Reg Anesth Pain Med. 2013;38(4):334-339.

40. Shonesy BC, Bluett RJ, Ramikie TS, et al. Genetic disruption of 2-arachidonoylglycerol synthesis reveals a key role for endocannabinoid signaling in anxiety modulation. Cell Rep. 2014;9(5):1644-1653.

41. Sing DC, Barry JJ, Cheah JW, Vail TP, Hansen EN. Long-acting opioid use independently predicts perioperative complication in total joint arthroplasty. J Arthroplasty. 2016;31(9 Suppl):170-174 e171.

42. Spofford CM, Ashmawi H, Subieta A, et al. Ketoprofen produces modality-specific inhibition of pain behaviors in rats after plantar incision. Anesth Analg. 2009;109(6):1992-1999.

43. Tanimura A, Yamazaki M, Hashimotodani Y, et al. The endocannabinoid 2-arachidonoylglycerol produced by diacylglycerol lipase alpha mediates retrograde suppression of synaptic transmission. Neuron. 2010;65(3):320-327.

44. Urban R, Scherrer G, Goulding EH, Tecott LH, Basbaum AI. Behavioral indices of ongoing pain are largely unchanged in male mice with tissue or nerve injury-induced mechanical hypersensitivity. Pain. 2011;152(5):990-1000.

45. Viader A, Ogasawara D, Joslyn CM, et al. A chemical proteomic atlas of brain serine hydrolases identifies cell type-specific pathways regulating neuroinflammation. Elife. 2016;5:e12345.

46. Wilkerson JL, Ghosh S, Bagdas D, et al. Diacylglycerol lipase beta inhibition reverses nociceptive behaviour in mouse models of inflammatory and neuropathic pain. Br J Pharmacol. 2016;173(10):1678-1692.

47. Wylde V, Rooker J, Halliday L, Blom A. Acute postoperative pain at rest after hip and knee arthroplasty: severity, sensory qualities and impact on sleep. Orthop Traumatol Surg Res. 2011;97(2):139-144.

48. Yu S, Szulc A, Walton S, Bosco J, Iorio R. Pain control and functional milestones in total knee arthroplasty: liposomal bupivacaine versus femoral nerve block. Clin Orthop Relat Res. 2017;475(1):110-117.

49. Zhu X, Conklin D, Eisenach JC. Cyclooxygenase-1 in the spinal cord plays an important role in postoperative pain. Pain. 2003;104(1-2): $15-23$.
Journal of Pain Research

\section{Publish your work in this journal}

The Journal of Pain Research is an international, peer reviewed, open access, online journal that welcomes laboratory and clinical findings in the fields of pain research and the prevention and management of pain. Original research, reviews, symposium reports, hypothesis formation and commentaries are all considered for publication.

\section{Dovepress}

The manuscript management system is completely online and includes a very quick and fair peer-review system, which is all easy to use. Visit http://www.dovepress.com/testimonials.php to read real quotes from published authors. 